\title{
DETERMINATION OF THE COMBINED MESIODISTAL WIDTHS OF THE PERMANENT MANDIBULAR INCISORS AND THE MAXILLARY AND MANDIBULAR CANINES AND PREMOLARS IN A GROUP OF EGYPTIAN CHILDREN IN GIZA GOVERNORATE. "A CROSS SECTIONAL STUDY"
}

\author{
Mohamed Hamdy*, Sherien Ezz El-Din ${ }^{* *}$ and Gehan Abo El-Nil***
}

\begin{abstract}
Objective: The aim of the study was to determine the combined mesiodistal widths of the permanent mandibular incisors and maxillary and mandibular canines and premolars in a group of Egyptian children in Giza governorate. Correlate between the combined mesiodistal widths of the teeth under study.
\end{abstract}

Subjects and methods: A sample of three hundred patients with an age range from twelve to fifteen years attending the outpatient clinics of Giza hospitals was considered. Upper and lower impressions were taken. Each impression was poured immediately in stone plaster. Mesio-distal widths of mandibular incisors and maxillary and mandibular canines and premolars was measured from the study models using digital caliper.

Results: No statistically significant difference in the mean mesiodistal tooth width between right and left sides in all teeth under study. Males showed larger mesiodistal tooth width than females. Positive correlations were found between mesiodistal teeth width of mandibular incisors and maxillary and mandibular canines and premolars.

Conclusions: The mesiodistal width of upper and lower canines and premolars can be predicted by measuring the mesiodistal width of lower incisors due to the positive correlation found between them.

\section{INTRODUCTION}

In order to improve the quality of dental care available, there is a great need for data on the mesiodistal crown dimensions of the individual teeth of Egyptian children. most data available on arch length analysis are for Northern European descent and only few data available for Egyptian population, this created the idea of the research as a

* MSC in Pediatric Dentistry, Cairo University

** Professor of Pediatric Dentistry, Faculty of Oral and Dental Medicine, Cairo University

*** Ass Professor of Pediatric Dentistry, Faculty of Oral and Dental Medicine, Cairo University 
part of a project applied on different Egyptian cities to collect data regarding mesiodistal widths of the permanent mandibular incisors and maxillary and mandibular canines and premolars in a group of Egyptian children.

\section{SUBJECTS AND METHODS}

A sample of three hundred patients with an age range from twelve to fifteen years attending the outpatient clinics of Giza hospitals was considered. Candidates selected with no previous orthodontic treatment. No morphologic anomalous in teeth shapes and number were included. Measurements were taken with the aid of a digital caliper and study casts for each subject. Patients were divided into Subgroups according to gender (males and females). No diagnostic radiographs were taken. A case chart was written for each candidate and clinical examination was carried out for them. Upper and lower impressions were taken. Each impression was poured immediately in stone plaster. Mesio-distal widths of mandibular incisors and maxillary and mandibular canines and premolars was measured from the study models using digital caliper.

\section{RESULTS}

The results of this study revealed :

* No statistically significant difference in the mean mesiodistal tooth width between right and left sides in all teeth under study.

* Males showed larger mesiodistal tooth width than females.

* Positive correlations were found between mesiodistal teeth width of mandibular incisors and maxillary and mandibular canines and premolars.

\section{DISCUSSION}

In this study the mesiodistal tooth width of mandibular incisors and maxillary and mandibular canines and premolars in a sample of three hundred candidates with an age range from twelve to fifteen years were studied. This range of age was selected so that one could study the permanent dentition with no or minimum wear on the proximal surface. Measurements were taken with the aid of a digital caliper and study casts for each subject.

The procedures for measuring the mesiodistal tooth width were performed as described by Hunter and Priest 1960 as the greatest mesiodistal measurement from the anatomic mesial contact point to the anatomic distal contact point of each tooth, measured parallel to the occlusal plane.

Digital calipers were advocated for scientific use and this was in harmony with Zilberman., 2003 who showed that digital calipers were more accurate when used to measure mesiodistal tooth width on study casts as compared to the measurements taken on virtual computerized models (OrthoCad).

Concerning the relationship between sex and the mesiodistal tooth width in this sample, this study showed a significant difference in the mean mesiodistal tooth width between males and females. The mean of the teeth size for the males were slightly larger than that for the females. This sexual dimorphism is consistent with the findings of the other investigators as Borgan., 2001. On the other hand this finding disagree with the findings of Nie and Lin.,1999 their findings concluded that sexual dimorphism for teeth size did not exist.

As regards the difference in mesiodistal tooth width of mandibular incisors and maxillary and mandibuler canine and premolars for right and left sides, it was found that there were no statistically significant differences between the two sides in all teeth under study. This finding was similar to that reported by Zilberman., 2003. 


\section{CONCLUSIONS}

Mesiodistal width of teeth in this sample of Egyptian children differ than mesiodistal width of teeth in other population. So pediatric dentists and orthodontists should rely on data of Egyptian children when planning their line of treatment. The mesiodistal width of upper and lower canines and premolars can be predicted by measuring the mesiodistal width of lower incisors due to the positive correlation found between them.

\section{REFERENCES}

1. Hunter, S.W. and Priest, R.W. Errors and discrepancies in measurement of tooth size. J. Dent. Res. 39:405-414, 1960.

2. Nie Q.D. and Lin J.A. Comparison of intermaxillarv tooth Size discrepancies among different malocclusion groups. Am J Orthod Dentofacial Orthop 116:539-544, 1999.

3. Borgan B.E. Dental arch dimensions analysis among Jordanian schoolchildren. MSc. Thesis. Faculty of Oral and Dental Medicine. Cairo University, 2001.

4. Zilberman L.R. Tooth measurments on virtual computerized models (OrthoCad) and digital calipers. Am J Orthod 79:343-37, 2003. 